CLINICAL STUDY

\title{
A longer interval without GH replacement and female gender are associated with lower bone mineral density in adults with childhood-onset GH deficiency: a KIMS database analysis
}

\author{
Nicholas A Tritos, Amir H Hamrahian ${ }^{1}$, Donna King ${ }^{4}$, Susan L Greenspan ${ }^{2}$, David M Cook ${ }^{3}$, Peter J Jönsson ${ }^{4}$, \\ Michael P Wajnrajch ${ }^{5}$, Maria Koltowska-Häggstrom ${ }^{4}$ and Beverly M K Biller \\ Neuroendocrine Unit, Massachusetts General Hospital and Harvard Medical School, Zero Emerson Place, Suite 112, Boston, Massachusetts O2114, USA, \\ ${ }^{1}$ Department of Endocrinology, Diabetes and Metabolism, Cleveland Clinic, Cleveland, Ohio, USA, ${ }^{2}$ Department of Medicine, University of Pittsburgh, \\ Pittsburgh, Pennsylvania, USA, ${ }^{3}$ Department of Endocrinology, Oregon Health and Science University, Portland, Oregon, USA, ${ }^{4}$ Pfizer Inc., Sollenuna, SE- \\ 191 90, Sweden and ${ }^{5}$ Pfizer, Inc., New York City, New York, USA
}

(Correspondence should be addressed to N A Tritos; Email: ntritos@partners.org)

\begin{abstract}
Objective: Childhood-onset GH deficiency (COGHD) is associated with low bone mineral density (BMD). Adults with persistent COGHD may be at risk for insufficient bone accrual or bone loss during adulthood. The purpose of this study was to identify BMD predictors and to characterize the effects of GH replacement on BMD in COGHD adults with persistent GHD.

Design: Retrospective analysis of the KIMS database.

Methods: Variables predicting standardized BMD (sBMD) were identified. The effect of GH replacement (3 years) on BMD was examined.

Results: Three hundred and fourteen COGHD adults (148 women, 166 men; 62 non-naïve, 178 seminaïve, and 74 true naïve, depending on length and timing of previous GH replacement), who had BMD measured in lumbar spine (LS) and femoral neck (FN) at study entry.

In semi-naïve subjects, a longer gap in GH replacement between childhood and adulthood was predictive of lower SBMD in the FN $(r=-0.18, P=0.038)$. TSH deficiency predicted lower sBMD in the LS $(r=-0.16, P=0.052)$. In true naïve patients, a longer gap between onset of pituitary disease and study entry $(r=-0.35, P=0.012)$, and female gender $(r=-0.27, P=0.043)$ independently predicted lower sBMD in the FN. There were no differences in BMD increases between non-naïve, semi-naïve, and true naïve subjects on GH replacement.

Conclusions: In semi-naïve subjects a longer interval off GH replacement was associated with lower sBMD in the FN. Among true naïve patients, a longer gap between the onset of pituitary disease and GH replacement, and female gender predicted lower SBMD in the FN.
\end{abstract}

European Journal of Endocrinology 167 343-351

\section{Introduction}

GH deficiency (GHD) of either childhood or adult onset is associated with low bone mineral density (BMD), which may be more severe in childhood-onset GHD (COGHD) in comparison with adult onset GHD (1). Up to 40\% of patients with COGHD may have persistent GHD when retested in adulthood $(2,3,4)$. As GH may have an important role in optimizing bone accrual in individuals who have completed their statural growth (5), patients with COGHD persisting in adulthood may be at risk for insufficient bone accrual or bone loss as a result of discontinuation of GH replacement after completion of linear growth.

GH acts on bone both directly and indirectly via endocrine and paracrine syntheses of insulin-like growth factor 1 (IGF1) $(6,7,8,9,10)$. In addition to
GH and IGF1, several other hormones have significant effects on bone mineralization, including thyroid hormone, glucocorticoids, and sex steroids (11, 12, 13, 14). Patients with COGHD may have multiple pituitary hormone deficiencies in addition to GHD, the presence of which, along with hormone replacement therapies, may influence BMD in this population.

Studies on patients with COGHD and persistent GHD after the completion of linear growth have yielded mixed results with regards to BMD outcomes in response to GH replacement, with some $(15,16,17)$, but not all (18), studies suggesting that the resumption of GH replacement in young adulthood may lead to additional increases in BMD.

To further clarify whether patients with COGHD persisting in adulthood are at risk for developing lower BMD in adulthood as a result of interruptions in 
GH replacement and characterize the role of additional pituitary hormone deficiencies on BMD in this population in a clinical practice setting, data from the large KIMS database were extracted and analyzed. This database comprises over 16000 adult GHD patients, including $\sim 3000$ COGHD individuals. To further investigate the effects of $\mathrm{GH}$ replacement in this population, data regarding BMD changes on $\mathrm{GH}$ replacement in adulthood were examined in these patients, who were stratified based on the presence of previous $\mathrm{GH}$ replacement and the length of treatment gap (interval) between $\mathrm{GH}$ replacement in childhood and adulthood.

\section{Materials and methods}

\section{Subjects}

The Pfizer International Metabolic Study (KIMS) database was queried for adult subjects of both genders, meeting all the following inclusion criteria: persistent GHD of childhood onset (based on stringent diagnostic criteria (19), Supplementary Table 1, see section on supplementary data given at the end of this article) as previously described (20) and recent BMD data available at KIMS entry (BMD measured by dual energy X-ray absorptiometry (DXA) on a Hologic, Lunar/GE or by Norland densitometer within 6 months before to 1 month after beginning GH replacement in adulthood).

A subpopulation was then identified, additionally meeting the following inclusion criteria: continuous (at least $90 \%$ of the time) $\mathrm{GH}$ replacement for 3 years since KIMS entry and BMD data available at 3 years since study entry, measured by DXA on the same densitometer used to acquire baseline BMD data.

All study subjects had provided written informed consent at the time of enrollment into KIMS. The study was conducted according to the principles of the Declaration of Helsinki (21). The majority of subjects were enrolled in European study centers.

\section{Methods}

The KIMS database was queried to extract demographic and clinical data on all study subjects, based on information submitted by each participating clinical center. Data extracted included age at diagnosis of pituitary disease, age at diagnosis of GHD, age at KIMS entry, duration of GHD (estimated as the difference between age at KIMS entry minus age at diagnosis of GHD), duration of GH replacement in childhood, gap (interval) between $\mathrm{GH}$ replacement in childhood and adulthood (i.e. KIMS entry), gender, body weight, height SDS and body mass index (BMI), prevalent fracture, cause of $\mathrm{GHD}$, peak $\mathrm{GH}$ response on stimulation testing, type and number of additional pituitary hormone deficiencies, glucocorticoid replacement dose (converted to hydrocortisone equivalent dose, using a relative potency for cortisone acetate: hydrocortisone: prednisone or prednisolone: dexamethasone of $25 \mathrm{mg}$ : $20 \mathrm{mg}$ : $5 \mathrm{mg}$ : $0.6 \mathrm{mg}$ ), and levothyroxine replacement dose (when available) (22). Study subjects were classified as being non-naïve (treated continuously or being off $\mathrm{GH}$ replacement shorter than 6 months before enrollment into KIMS), semi-naïve (treated in childhood, but being off $\mathrm{GH}$ replacement longer than 12 months before KIMS entry), and true-naïve (patients never treated in childhood, who were beginning $\mathrm{GH}$ replacement at KIMS entry).

Laboratory data included IGF1 SDSs calculated based on serum IGF1 levels measured centrally in the laboratories listed below.

Serum IGF1 levels were assayed at Kabi Pharmacia, Stockholm, Sweden between 1994 and October 1997. Thereafter, IGF1 assays were performed at Sahlgrenska University Hospital, Gothenburg, Sweden. Between 1994 and November 2002, a RIA was used to assay IGF1 in serum specimens after acid/ethanol precipitation of IGF-binding proteins (Nichols Institute, San Juan Capistrano, CA, USA) (16). Subsequently (until September 2006), a chemiluminescence immunoassay was employed (Nichols Advantage System). Thereafter, the Immulite 2500 (DPC Siemens, Deerfield, IL, USA) method has been used to measure serum IGF1 levels.

The following formulae were used to calculate IGF1 SDS: $S D S=(\ln ($ IGF1 $)-(5.95-0.0197 \times$ age $)) / 0.282$ (between 1994-1997); $\mathrm{SDS}=(\ln (\mathrm{IGF} 1)-(15.92-$ $0.0146 \times$ age))/0.272 (between 1997-2002); and (from 2002 onwards) based on data from the study of Brabant et al. (23).

Bone densitometric data extracted included BMD and $\mathrm{Z}$ scores from two skeletal sites (including posterioranterior lumbar spine (LS) and femoral neck (FN)). At any skeletal site, measured BMD values vary between different densitometers, as diverse bone edge detection algorithms and calibration standards are employed by densitometer manufacturers. Predictive equations have been developed in order to facilitate direct comparisons between BMD data obtained on different densitometers $(24,25)$. These equations yield standardized BMD (sBMD) values, which can be used in population studies. Herein, sBMD data were calculated based on BMD values and the predictive equations for LS and FN, as previously described $(20,24,25)$.

\section{Statistical analysis}

The Student's $t$-test was used to analyze normally distributed data and the Wilcoxon rank-sum test or the sign rank test was used in the analysis of nonparametric variables. Univariate as well as stepwise, multivariate regression analysis was used to identify variables independently predicting sBMD (in LS or FN). Independent variables introduced in the multivariate regression analysis model were subject age, age at onset 


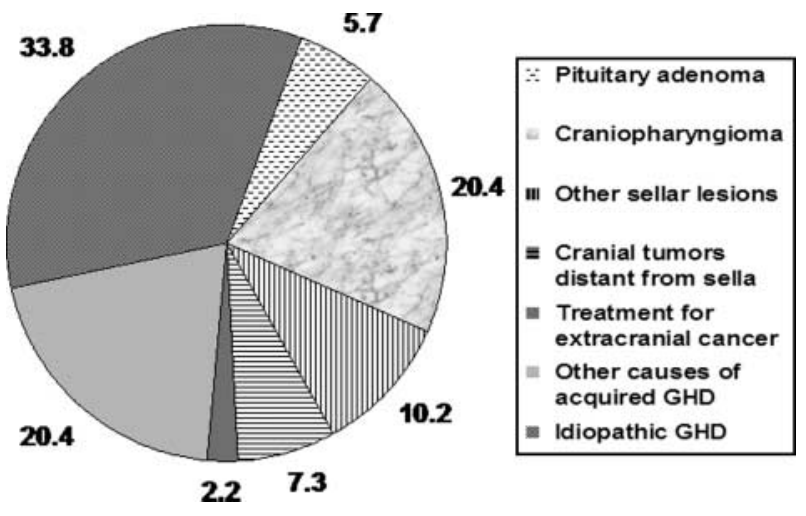

Figure 1 Causes of GHD in the study population (percent total) based on a previously defined classification list (33).

of pituitary disease, age at diagnosis of $\mathrm{GHD}$, gender, height SDS (calculated based on published reference data) (26), interval between onset of pituitary disease and study entry, estimated GHD duration, estimated duration of pediatric GH replacement, cause of GHD (idiopathic vs all others), gap (interval) length between GH replacement in childhood and KIMS entry, peak $\mathrm{GH}$ level on stimulation testing, and the presence or absence of deficiencies of gonadotropins, corticotropin, TSH, or antidiuretic hormone. Nominal variables were assigned numerical codes for the purpose of analysis.
The Statistical Analysis System (SAS Institute, Inc., Cary, NC, USA) was used in all statistical procedures. Data were expressed as median (10th percentile, 90th percentile) or mean \pm s.E.M., and statistical significance was accepted at a $P<0.05$ level.

\section{Results}

There were 314 adult subjects, all diagnosed with COGHD based on stringent criteria (Supplementary Table 1) as previously described (20). There were 148 women (47.1\%) and 166 men (52.9\%). The majority of study subjects was Caucasian from western European countries and were enrolled in 89 participating centers. Data on the causes of GHD in this population are shown in Fig. 1. The most common single cause of GHD was idiopathic $(33.8 \%)$, followed by craniopharyngioma $(20.4 \%)$. Pituitary adenoma was relatively uncommon $(5.7 \%)$, as anticipated in a population of patients with COGHD, and was present in $14.9 \%$ of true naïve, $2.2 \%$ of semi-naïve, and $4.8 \%$ of non-naïve patients $(P=N S)$.

Additional characteristics of the study population, stratified as being non-naïve (62 patients, $19.7 \%$ ), seminaïve (178 subjects, $56.7 \%$ ), or true naïve ( 74 patients, $23.6 \%$ ), are shown in Table 1 .

True naïve subjects were older at the time of the onset of pituitary disease or at the time of diagnosis of GHD in

Table 1 Characteristics of the study population stratified by the gap length between GH replacement in childhood and adulthood. Study subjects were classified as being non-naïve (treated continuously or being off GH replacement shorter than 6 months before enrollment into KIMS), semi-naïve (treated in childhood but being off GH replacement longer than 12 months before KIMS entry), and true-naïve (patients never treated in childhood, who were beginning GH replacement at KIMS entry).

\begin{tabular}{|c|c|c|c|c|c|c|}
\hline Variable & $\begin{array}{l}\text { Non-naïve } \\
(n=62)\end{array}$ & $\begin{array}{l}\text { Semi-naïve } \\
(n=178)\end{array}$ & $\begin{array}{l}\text { True naïve } \\
\quad(n=74)\end{array}$ & $\begin{array}{c}\text { Non-naïve vs } \\
\text { semi-naïve } \\
P \text { value }\end{array}$ & $\begin{array}{c}\text { Semi-naïve vs } \\
\text { true naïve } \\
P \text { value }\end{array}$ & $\begin{array}{c}\text { Non-naïve vs } \\
\text { true naïve } \\
P \text { value }\end{array}$ \\
\hline $\begin{array}{l}\text { Age at onset of pituitary disease } \\
\text { (years) }\end{array}$ & $9.6(2.9,16.8)$ & $9.1(3.6,14.8)$ & $14.4(7.5,17.3)$ & NS & $<0.001$ & $<0.001$ \\
\hline Age at diagnosis of GHD (years) & $14.0(4.8,23.0)$ & $14.5(5.9,32.3)$ & $21.2(15.6,45.7)$ & NS & $<0.001$ & $<0.001$ \\
\hline Age at study entry (years) & $22.5(18.4,39.6)$ & $27.5(19.8,39.8)$ & $30.6(18.2,51.6)$ & 0.022 & 0.095 & $<0.010$ \\
\hline Estimated duration of GHD (years) & $11.7(1.4,25.8)$ & $12.2(0.4,24.2)$ & $1.5(0,16.8)$ & NS & $<0.001$ & $<0.001$ \\
\hline $\begin{array}{l}\text { Total years GH replaced before } \\
\text { study entry }\end{array}$ & $8.0(1.1,14.0)$ & $6.0(2.0,12.0)$ & $0(0,0)$ & 0.096 & NA & NA \\
\hline IGF1 SDS at study entry & $-1.4(-4.9,1.8)$ & $-4.1(-6.3,-2.3)$ & $-4.1(-7.0,-2.3)$ & $<0.001$ & NS & $<0.001^{*}$ \\
\hline $\begin{array}{l}\text { Number of additional pituitary } \\
\text { hormone deficiencies }\end{array}$ & $3(0,4)$ & $3(0,4)$ & $3(0,4)$ & NS & NS & NS \\
\hline Height $(\mathrm{cm})$ & $163(150,177)$ & $162(149,178)$ & $159(139,174)$ & $\mathrm{NS}^{*}$ & $0.038^{*}$ & $0.030^{*}$ \\
\hline Height SDS at study entry & $-0.86(-3.18,0.52)$ & $-1.30(-3.47,0.28)$ & $-1.63(-4.40,0.40)$ & $\mathrm{NS}^{*}$ & $0.070^{*}$ & $0.023^{*}$ \\
\hline BMI $\left(\mathrm{kg} / \mathrm{m}^{2}\right)$ & $24.1(19.1,33.5)$ & $25.1(19.3,35.4)$ & $27.4(20.9,34.9)$ & NS & $<0.010$ & 0.011 \\
\hline Lumbar spine sBMD $\left(\mathrm{mg} / \mathrm{cm}^{2}\right)$ & $989.5(795.9,1183)$ & $1005(817.4,1247)$ & $989.5(809.4,1190)$ & NS & NS & NS \\
\hline Lumbar spine $Z$ score & $-1.8(-3.0,1.6)$ & $-1.2(-2.3,1.1)$ & $-1.8(-2.9,0.4)$ & NS & 0.087 & $\mathrm{NS}^{*}$ \\
\hline $\begin{array}{l}\text { Proportion of subjects with } \\
\text { lumbar spine } Z \text { score }<-2.0\end{array}$ & $29.4 \%$ & $17.6 \%$ & $37.5 \%$ & NS & NS & NS \\
\hline Femoral neck sBMD $\left(\mathrm{mg} / \mathrm{cm}^{2}\right)$ & $885.6(690.6,1084)$ & $866.9(682.1,1160)$ & $840.9(689.3,1128)$ & NS & NS & 0.099 \\
\hline Femoral neck $Z$ score & $-0.4(-1.8,1.3)$ & $-0.9(-2.8,0.5)$ & $-0.6(-2.1,1.3)$ & $0.074^{*}$ & $\mathrm{NS}^{*}$ & $\mathrm{NS}^{*}$ \\
\hline $\begin{array}{l}\text { Proportion of subjects with } \\
\text { femoral neck } Z \text { score }<-2.0\end{array}$ & $7.1 \%$ & $20.4 \%$ & $13.6 \%$ & NS & NS & NS \\
\hline $\begin{array}{l}\text { Proportion of subjects with } \\
\text { prevalent fracture }\end{array}$ & $16.4 \%$ & $19.5 \%$ & $29.2 \%$ & NS & NS & NS \\
\hline
\end{tabular}

Data shown as median (10th and 90th percentiles). Unless otherwise noted, $P$ values were obtained using the Wilcoxon rank-sum test. ${ }^{\star} P$ values were obtained using the $t$-test. NS, not significant. 
comparison with those in the other two groups (nonnaïve and semi-naïve). In addition, true naïve subjects were slightly older than semi-naïve patients at the time of study entry, the latter also being slightly older than non-naïve subjects at study entry. True naïve subjects were shorter in height and heavier (based on BMI data) than patients belonging to the other two groups. Non-naïve subjects had higher IGF1 SDS at time of study entry in comparison with those belonging to the other two groups, likely as a result of continuous $\mathrm{GH}$ replacement.

Glucocorticoid replacement therapy was reported in $\sim 59 \%$ of subjects in all three groups $(P=N S)$, of whom $81 \%$ were treated with hydrocortisone, $14 \%$ with cortisone acetate, and the remaining subjects with prednisolone or dexamethasone. Glucocorticoid dosing, expressed as hydrocortisone equivalent dose, was similar in all three groups (non-naïve: $20 \mathrm{mg} /$ day (10, $30 \mathrm{mg}$ /day), semi-naïve: $20 \mathrm{mg} /$ day (10, $30 \mathrm{mg} /$ day), true naïve: $20 \mathrm{mg} /$ day (10, $30 \mathrm{mg} /$ day), $P=\mathrm{NS}$ ).

At study entry, there were no significant differences in sBMD values between the three subject groups. However, non-naïve patients showed a trend towards higher sBMD in the FN in comparison with true naïve patients. In addition, semi-naïve patients showed a trend towards higher BMD Z scores in the LS than true naïve subjects, and non-naïve patients showed a trend towards higher BMD Z scores in the FN than semi-naïve subjects.

In semi-naïve patients, there was a median (10th percentile, 90th percentile) gap (interval) of 8.2 years (2.1 and 20.8 years) between pediatric GH replacement and onset of $\mathrm{GH}$ replacement in adulthood. In this group, there was an association between duration of pediatric GH replacement and age at termination of pediatric $\mathrm{GH}$ replacement $(r=0.25, P=0.001)$.

To examine the association between sBMD and the gap in $\mathrm{GH}$ replacement in this group, both univariate and multivariate regression analyses were conducted. On univariate analysis, there was a negative association between sBMD in the LS and the gap in GH replacement $(r=-0.17, P=0.027$, Fig. 2a) as well as a negative association between sBMD in the $\mathrm{FN}$ and the gap in $\mathrm{GH}$ replacement ( $r=-0.23, P<0.010$, Fig. $2 b)$.

On multivariate regression analysis, the negative association between sBMD and gap in $\mathrm{GH}$ replacement remained significant in the $\mathrm{FN}(r=-0.18, P=0.038)$ but not in the LS. We also examined the association between sBMD in the $\mathrm{FN}$ and gap in $\mathrm{GH}$ replacement in the subgroup of subjects aged $<25$ years old at study entry $(n=79)$. The gap in GH replacement between pediatric and adult $\mathrm{GH}$ replacement in this population was 4.5 years (1.4 and 8.3 years). There was no association between sBMD and gap in GH replacement in this subject subgroup.

TSH deficiency (defined as the presence of low free thyroxine levels with inappropriately normal serum TSH) was an independent predictor of lower sBMD in
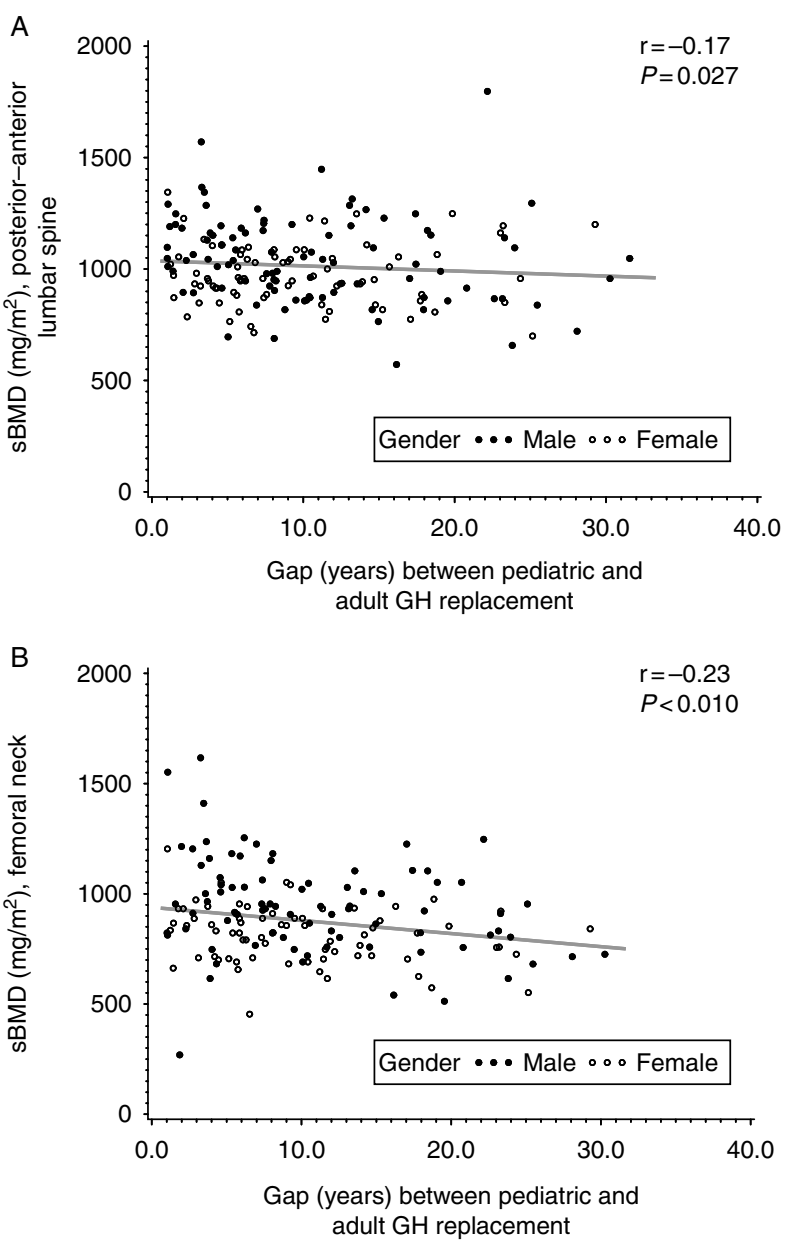

Figure 2 (a) Association between sBMD (posterior anterior lumbar spine) and gap length between GH replacement in childhood and adulthood in semi-naïve subjects (treated in childhood but being off $\mathrm{GH}$ replacement longer than 12 months before KIMS entry). (b) Association between sBMD (femoral neck) and gap length between $\mathrm{GH}$ replacement in childhood and adulthood in semi-naïve subjects (treated in childhood but being off $\mathrm{GH}$ replacement longer than 12 months before KIMS entry).

the LS $(r=-0.16, P=0.036)$. However, in the final regression model, which additionally included peak $\mathrm{GH}$ level on stimulation testing as a possible predictor, the statistical significance of this observation became borderline $(r=-0.16, P=0.052)$. Of note, there was no association between sBMD and levothyroxine dose (in $\mu \mathrm{g} / \mathrm{kg}$ ) in these patients (data not shown).

To identify predictors of sBMD in the other two groups (non-naïve and true naïve subjects), additional regression analyses were conducted. In non-naïve subjects, older age at study entry $(r=0.41, P=0.027)$ and female gender $(r=-0.40, P=0.018)$ independently predicted SBMD in the FN (higher sBMD in older patients and lower sBMD in women) on multivariate regression analysis. No predictors of sBMD in the LS were identified in this group. 
Table 2 Characteristics of the study subpopulation followed longitudinally (on GH replacement in adulthood after study entry). Study subjects were classified as being non-naïve (treated continuously or being off GH replacement shorter than 6 months before enrollment into KIMS), semi-naïve (treated in childhood but being off GH replacement longer than 12 months before KIMS entry), and true-naïve (patients never treated in childhood, who were beginning GH replacement at KIMS entry).

\begin{tabular}{|c|c|c|c|c|c|c|}
\hline Variable & $\begin{array}{l}\text { Non-naïve } \\
(n=26)\end{array}$ & $\begin{array}{l}\text { Semi-naïve } \\
\quad(n=52)\end{array}$ & $\begin{array}{l}\text { True naïve } \\
\quad(n=19)\end{array}$ & $\begin{array}{c}\text { Non-naïve vs } \\
\text { semi-naïve } \\
P \text { value }\end{array}$ & $\begin{array}{c}\text { Semi-naïve } \\
\text { vs true naïve } \\
P \text { value }\end{array}$ & $\begin{array}{c}\text { Non-naïve vs } \\
\text { true naïve } \\
P \text { value }\end{array}$ \\
\hline $\begin{array}{l}\text { Age at onset of pituitary } \\
\text { disease (years) }\end{array}$ & $10.3(2.7,17.1)$ & $8.8(3.7,13.6)$ & $11.9(5.9,17.5)$ & NS & $<0.010^{*}$ & NS \\
\hline Age at diagnosis of GHD (years) & $14.9(4.1,24.3)$ & $13.4(5.2,30.7)$ & $20.4(15.3,56.4)$ & NS & $<0.001$ & $<0.001$ \\
\hline Age at study entry (years) & $24.9(19.4,44.7)$ & $26.2(19.4,36.5)$ & $30.6(17.4,57.6)$ & NS & NS & NS \\
\hline $\begin{array}{l}\text { Estimated duration of GHD } \\
\text { (years) before study entry }\end{array}$ & $13.0(1.2,28.0)$ & $11.9(0.4,22.0)$ & $1.0(0.0,27.6)$ & NS & $<0.001$ & $<0.010$ \\
\hline $\begin{array}{l}\text { Total years } \mathrm{GH} \text { replaced before } \\
\text { study entry }\end{array}$ & $7.8(1.0,14.0)$ & $5.5(2.0,13.0)$ & $0(0,0)$ & NS & NA & NA \\
\hline IGF1 SDS at study entry & $-0.6(-4.0,2.0)$ & $-3.9(-5.5,-1.7)$ & $-3.5(-4.3,-1.7)$ & $<0.001$ & NS & $<0.010^{\star}$ \\
\hline $\begin{array}{l}\text { Number of additional pituitary } \\
\text { hormone deficiencies }\end{array}$ & $3(0,4)$ & $3(0,4)$ & $2(0,4)$ & NS & NS & NS \\
\hline Height $(\mathrm{cm})$ at study entry & $165(156,177)$ & $167(148,180)$ & $161(134,173)$ & NS & NS & NS \\
\hline Height SDS at study entry & $-0.78(-3.14,0.67)$ & $-1.07(-3.30,0.40)$ & $-1.62(-5.09,0.82)$ & NS & NS* & NS \\
\hline BMI $\left(\mathrm{kg} / \mathrm{m}^{2}\right)$ at study entry & $24.7(18.9,36.8)$ & $25.2(19.7,35.4)$ & $26.5(20.0,33.8)$ & NS & NS & NS \\
\hline $\mathrm{GH}$ dose (mg/day) at 3 years & $0.5(0.3,0.9)$ & $0.6(0.3,1.0)$ & $0.5(0.1,1.0)$ & NS & NS & NS \\
\hline IGF1 SDS at 3 years & $0.3(-3.1,1.9)$ & $-0.4(-3.0,1.3)$ & $-0.3(-1.9,1.9)$ & NS & NS & NS \\
\hline
\end{tabular}

Data shown as median (10th and 90th percentiles). Unless otherwise noted, $P$ values were obtained using the Wilcoxon rank-sum test. ${ }^{\star} P$ values were obtained using the $t$-test.

In true naïve subjects, greater height SDS at study entry $(r=0.43, P<0.001)$ and higher peak GH level on stimulation testing $(r=0.35, P=0.003)$ independently predicted higher SBMD in the LS on multivariate regression analysis. In addition, a longer gap between the onset of pituitary disease and study entry $(r=-0.35, P=0.012)$, and female gender $(r=-0.27$, $P=0.043)$ independently predicted lower sBMD in the FN of true naïve patients on multivariate regression analysis.

We also examined predictors of SBMD in the FN in the subgroup of true naïve subjects aged $<25$ years old at study entry $(n=29)$, using multivariate regression analysis. A longer gap between the diagnosis of GHD and onset of $\mathrm{GH}$ replacement in this subject subgroup $(r=-0.41, P=0.047)$ independently predicted lower sBMD in the FN. In addition, greater height SDS at study entry independently predicted higher sBMD in the FN $(r=0.44, P=0.048)$. Patient characteristics of the study subpopulation followed on GH replacement for 3 years after study entry, stratified as being non-naïve (26 patients, $26.8 \%$ ), semi-naïve (52 subjects, $53.6 \%$ ), or true naïve (19 patients, $19.6 \%$ ), are shown in Table 2.

Data on the effects of GH replacement on BMD (absolute and percent changes) in the LS and FN are shown in Table 3. There were significant increases in BMD in the LS of all three patient groups, including non-naïve, semi-naïve, and true naïve patients. In addition, there were significant increases in BMD in the FN of non-naïve and semi-naïve subjects. However, in true naïve subjects there was a statistically nonsignificant increase in BMD in the FN. This finding did not change if true naïve subjects with IGF1 SDS $<-1.0$ at 3 years were removed (data not shown). There were

Table 3 Effects of 3 years of GH replacement in adulthood on BMD stratified by the gap length between GH replacement in childhood and adulthood. Study subjects were classified as being non-naïve (treated continuously or being off GH replacement shorter than 6 months before enrollment into KIMS), semi-naïve (treated in childhood but being off GH replacement longer than 12 months before KIMS entry), and true-naïve (patients never treated in childhood, who were beginning GH replacement at KIMS entry). $P$ values shown refer to within-subgroup changes over baseline.

\begin{tabular}{llccccc}
\hline Variable & $\begin{array}{l}\text { Non-naïve } \\
(n=26)\end{array}$ & $\begin{array}{l}\text { Non-naïve } \\
\boldsymbol{P} \text { value }\end{array}$ & $\begin{array}{l}\text { Semi-naïve } \\
(n=52)\end{array}$ & $\begin{array}{l}\text { Semi-naïve } \\
\boldsymbol{P} \text { value }\end{array}$ & $\begin{array}{l}\text { True naïve } \\
(n=19)\end{array}$ & $\begin{array}{l}\text { True naïve } \\
\boldsymbol{P} \text { value }\end{array}$ \\
\hline $\begin{array}{c}\text { Absolute change in lumbar } \\
\text { spine BMD }\left(\mathrm{g} / \mathrm{cm}^{2}\right)\end{array}$ & $\begin{array}{c}0.015 \\
(-0.050,0.120)\end{array}$ & 0.053 & $\begin{array}{l}0.040 \\
(-0.080,0.160)\end{array}$ & $<0.010$ & 0.060 \\
$(-0.060,0.170)$ & 0.029 \\
$\begin{array}{c}\text { Percent change in lumbar } \\
\text { spine BMD }(\%)\end{array}$ & $\begin{array}{c}1.59 \\
(-3.55,12.37)\end{array}$ & 0.035 & $\begin{array}{c}3.91 \\
(-6.59,16.90)\end{array}$ & $<0.010$ & $\begin{array}{c}6.00 \\
(-6.74,17.89)\end{array}$ & 0.032 \\
$\begin{array}{c}\text { Absolute change in femoral } \\
\text { neck BMD }\left(\mathrm{g} / \mathrm{cm}^{2}\right)\end{array}$ & $\begin{array}{c}0.020 \\
(-0.020,0.210)\end{array}$ & 0.011 & $\begin{array}{c}0.020 \\
(-0.100,0.140)\end{array}$ & 0.013 & $\begin{array}{c}0.065 \\
(-0.140,0.150)\end{array}$ & $0.177(\mathrm{NS})$ \\
$\begin{array}{c}\text { Percent in femoral neck } \\
\text { BMD }(\%)\end{array}$ & $\begin{array}{c}2.78 \\
(-2.08,22.45)\end{array}$ & $<0.010$ & $\begin{array}{c}2.89 \\
(-10.1,14.29)\end{array}$ & 0.015 & $\begin{array}{c}7.17 \\
(-13.5,19.0)\end{array}$ & $0.173(\mathrm{NS})$ \\
\hline
\end{tabular}

Data shown as median (10th and 90th percentiles). $P$ values were obtained using the Sign rank test. 
no predictors of BMD response to $\mathrm{GH}$ replacement identified on regression analysis (data not shown). There were no statistically significant differences between the changes (absolute or percent) in BMD (in the LS or FN) between the three groups, including nonnaïve, semi-naïve, and true naïve patients $(P=N S)$.

\section{Discussion}

COGHD persists in adulthood in a subset of patients, who may be at risk for developing lower BMD as a result of failure of bone mineral accrual or bone loss during delayed or interrupted $\mathrm{GH}$ replacement in adulthood. Such interruptions may be common among pediatric patients after the completion of statural growth, who may not continue to follow-up with their treating physician or transition their care to an adult endocrinologist (27).

The hypothesis of this study was that interruptions in $\mathrm{GH}$ replacement in adulthood may be detrimental to BMD. In addition, it was hypothesized that deficiencies of other pituitary hormones, besides GH, may influence BMD, as has been shown in a population of adult onset GHD subjects (20). To facilitate direct comparisons between BMD values obtained on densitometers from different manufacturers, densitometric data were converted to SBMD to allow cross-sectional analysis of BMD data $(24,25)$.

The study population was defined to include COGHD subjects with persistent GHD in adulthood, based on stringent diagnostic criteria, who were stratified based on the presence and length of treatment gap (interval) length between pediatric and adult GH replacement. This stratification resulted in three groups, including non-naïve, semi-naïve, and true naïve. In semi-naïve patients, a longer gap in GH replacement was associated with lower sBMD in the FN. In true naïve patients, a longer interval between the onset of pituitary disease and GH replacement in adulthood as well as female gender was independently associated with lower SBMD in the FN. In the LS of semi-naïve patients, TSH deficiency (central hypothyroidism) was independently associated with lower sBMD.

These findings are consistent with a relevant role of GH during bone mineral accrual in young adulthood (28) and suggest that interruptions in GH replacement during adulthood may be detrimental to bone health. It is possible that GH replacement may help to prevent bone loss and preserve bone mineralization during adulthood. On subgroup analysis, we found no association between the gap in GH replacement and sBMD in semi-naïve patients $<25$ years old at study entry. However, not only was the subgroup size considerably smaller but also the gap in $\mathrm{GH}$ replacement was considerably shorter. Thus, this additional analysis does not exclude the possibility that some of our patients failed to accrue bone mass during the gap period.
It is also conceivable that patients with longer gaps in GH replacement between childhood and adulthood were undertreated as children, thus accounting for their lower bone density. Of note, data on pediatric GH dose replacement were not available in our study. However, to account for this possibility, we have included height SDS and duration of pediatric GH replacement in our analysis and noted that our findings remained robust to this adjustment.

As such, these observations are of clinical significance. Based on the present data, an estimate of a safe gap in GH replacement (with regards to BMD) cannot be made. However, the current findings underscore the importance of minimizing the interval in GH replacement during adulthood, which might help to optimize skeletal outcomes. Taken together with previously published data suggesting that a gap in GH replacement may also be associated with less favorable systemic lipid profiles (29), our observations are consistent with the notion that interruptions in $\mathrm{GH}$ replacement during adulthood may be detrimental to overall health.

The mechanism mediating the association between TSH deficiency and lower SBMD is not clear and could involve a consequence of excessive or insufficient thyroid hormone replacement. It is also possible that GHD severity could be a confounder in the relationship between TSH deficiency and SBMD, as the degree of TSH deficiency has been associated with GHD severity (30). It may also be noted that exogenous thyroid hormone excess has been associated with lower BMD (12). As free thyroxine levels were not available in most patients, additional data are needed to clarify this association. Nevertheless, the present observations suggest that thyroid hormone replacement should be carefully titrated to minimize its possible adverse effects on bone health $(14,31)$.

An additional objective of this study was to examine the effects of GH replacement in COGHD subjects with persistent GHD in adulthood. This goal was considered to be of interest, as the findings of previous studies have not been consistent (Table 4) $(15,16,17,18)$. This study's observations indicated that there was a significant increase in BMD in the LS of non-naïve, semi-naïve, and true naïve subjects after 3 years of $\mathrm{GH}$ replacement (without significant differences between the three groups) and are consistent with a relevant role of GH replacement in bone accrual in this population (27).

Broadly similar were the effects of 3 years of $\mathrm{GH}$ replacement on BMD in the FN, with the exception that the increase in FN BMD was not statistically significant in true naïve subjects. It may be noted that the subgroup of true naïve subjects followed prospectively was relatively small, which may have limited our ability to detect a statistically significant change in BMD or identify predictors of response to $\mathrm{GH}$ replacement. In addition, data on compliance with GH replacement throughout the study period were not available, nor 
Table 4 Effects of GH replacement on lumbar spine BMD (or $Z$ score) in randomized controlled clinical trials, including COGHD young adults with GHD persisting in adulthood, as well as the present uncontrolled study.

\begin{tabular}{|c|c|c|c|c|c|c|}
\hline References & $\begin{array}{c}\text { Publication } \\
\text { year }\end{array}$ & $\begin{array}{l}\text { Study } \\
\text { population } \\
\text { size }(n)\end{array}$ & $\begin{array}{l}\text { Study } \\
\text { duration } \\
\text { (months) }\end{array}$ & $\begin{array}{l}\text { Change over baseline } \\
\text { in treated group } \\
\text { (mean } / \text { median) }\end{array}$ & $\begin{array}{l}\text { Change over baseline } \\
\text { in control group } \\
\text { (mean/median) }\end{array}$ & $P$ value \\
\hline $\begin{array}{l}(15) \\
(16) \\
(18) \\
(17) \\
\text { Present study }\end{array}$ & $\begin{array}{l}2003 \\
2003 \\
2005 \\
2009\end{array}$ & $\begin{array}{r}149 \\
64 \\
58 \\
160 \\
97\end{array}$ & $\begin{array}{l}24 \\
24 \\
24 \\
24 \\
36\end{array}$ & $\begin{array}{l}6.1 \% \text { (BMD) } \\
5.2 \% \text { (BMD) } \\
-0.29 \text { ( } Z \text { score) } \\
6.0 \% \text { (BMD) } \\
1.59 \% \text { (non-naïve) } \\
3.91 \% \text { (semi-naïve) } \\
6.0 \% \text { (true naïve) }\end{array}$ & $\begin{array}{l}3.1 \% \text { (BMD) } \\
1.3 \% \text { (BMD) } \\
-1.08 \text { ( } Z \text { score) } \\
2.0 \% \text { (BMD) } \\
\text { Not applicable }\end{array}$ & $\begin{array}{r}0.027 \\
0.001 \\
0.086 \\
<0.001 \\
<0.05^{\star}\end{array}$ \\
\hline
\end{tabular}

${ }^{\star} P$ values for percent increase in BMD (over baseline) as follows: $P=0.035$ (non-naïve); $P<0.010$ (semi-naive); $P=0.032$ (true naïve).

were data on calcium and vitamin D intake, all of which could influence the effects of GH replacement on BMD.

Strengths of this study include the stringent definition of GHD and the overall large study population. However, any study based on analysis of previously collected data has limitations, arising from the inclusion of subjects with available data, based on local clinical practice. As a result of applying stringent inclusion criteria, $10.5 \%$ of COGHD patients in the KIMS database were eligible to participate and were included in this analysis. In addition, the current data pertain to a population of predominantly Caucasian patients and may not be applicable to patients of other racial groups. True naïve adult subjects with COGHD are rather atypical in practice, which justifies analysis of these data as a separate group in the authors' opinion.

Another study limitation involves the lack of densitometer cross-calibration between participating centers. It may be noted that central quality control and cross-calibration procedures are generally employed in clinical trials. However, this study represents a pharmaco-epidemiological survey of data obtained in clinical practice. To mitigate the limitations arising from the lack of cross-calibration between densitometers, we have employed the sBMD methodology, as already described.

In pediatric GHD populations (areal), BMD (as measured by DXA) is influenced by patients' height $(27,28)$. Our study population consisted of adult, rather than pediatric, COGHD patients. Nevertheless, to minimize any potential confounding effect of patients' height, this variable was introduced as a potential predictor in all multivariate analyses.

It may be noted that sBMD values in true naïve patients were not significantly decreased in comparison with those in semi-naïve or non-naïve patients at study entry. However, true naïve patients were significantly older at the time of onset of pituitary disease and GHD diagnosis and had a shorter GHD duration in comparison with the other two groups at study entry. As a consequence, it is possible that true naïve patients may have been relatively protected from the deleterious effects of untreated GHD on bone density.
This study's findings explained a relatively small proportion of the total variability in sBMD, underscoring the potential role of additional genetic, nutritional, and lifestyle factors that may influence sBMD. Nevertheless, the aims of this study were limited to the investigation of the role of the gap (interval) in $\mathrm{GH}$ replacement as well as endocrine variables as potential predictors of bone mineralization.

A substantial proportion of our study subjects had $\mathrm{Z}$ scores $<-2.0$ in the LS. It has been suggested that isolated GHD of childhood or adult onset is associated with normal BMD (32). However, the majority of the subjects in this study had multiple pituitary hormone deficiencies limiting the applicability of the conclusions of the earlier article to our study (32). Of note, there were no available data on the time of fracture in our study population. Therefore, fracture incidence could not be estimated based on our data.

In conclusion, a longer gap in $\mathrm{GH}$ replacement in adults with COGHD persisting in adulthood (or a longer interval between the onset of pituitary disease and GH replacement in true naïve patients) was negatively associated with bone mineralization (in FN) in this population. TSH deficiency was also associated with lower bone mineralization (in LS) in semi-naïve subjects, albeit with borderline statistical significance. GH replacement for 3 years led to significant gains in BMD in most patient groups and skeletal sites. Overall, these findings, based on data from clinical practice, affirm the role of $\mathrm{GH}$ in optimizing bone accrual in COGHD patients in transition to adulthood and/or maintaining BMD during adulthood.

\section{Supplementary data}

This is linked to the online version of the paper at http://dx.doi.org/10. 1530/EJE-12-0070.

\section{Declaration of interest}

Drs N A Tritos, A H Hamrahian, S L Greenspan, D M Cook, and B M K Biller were not compensated for their contributions to this manuscript. $\mathrm{N}$ A Tritos has been a recipient of research funding and lecture fees 
from Pfizer, Inc.; spouse is an employee of Pfizer, Inc. A H Hamrahian has been a recipient of lecture fees from Novartis, Ipsen, and Pfizer and has served as a consultant to Ipsen and Pfizer, Inc. S L Greenspan has been a recipient of research funding from Eli Lilly, Warner Chilcott, Tarsa and has consulted and served on an advisory board for Amgen and Merck. D King, M P Wajnrajch, P J Jönsson and M KoltowskaHäggstrom are full-time employees of Pfizer, Inc. B M K Biller has been a recipient of research funding from Pfizer, Eli Lilly, Novo-Nordisk and Serono and has served on an advisory board and received consulting fees from Pfizer and Novo-Nordisk.

\section{Funding}

KIMS is sponsored by Pfizer, Inc.

\section{Acknowledgements}

All authors of this study would like to express their gratitude to the clinicians who provided the primary data on their patients.

\section{References}

1 Koranyi J, Svensson J, Gotherstrom G, Sunnerhagen KS, Bengtsson B \& Johannsson G. Baseline characteristics and the effects of five years of GH replacement therapy in adults with GH deficiency of childhood or adulthood onset: a comparative, prospective study. Journal of Clinical Endocrinology and Metabolism 200186 4693-4699. (doi:10.1210/jc.86.10.4693)

2 Nicolson A, Toogood AA, Rahim A \& Shalet SM. The prevalence of severe growth hormone deficiency in adults who received growth hormone replacement in childhood [see comment]. Clinical Endocrinology $1996 \mathbf{4 4}$ 311-316. (doi:10.1046/j.1365-2265. 1996.671492.x)

3 Aimaretti G, Baffoni C, Bellone S, Di Vito L, Corneli G, Arvat E, Benso L, Camanni F \& Ghigo E. Retesting young adults with childhood-onset growth hormone (GH) deficiency with GH-releasing-hormone-plus-arginine test. Journal of Clinical Endocrinology and Metabolism 200085 3693-3699. (doi:10.1210/jc.85.10. 3693)

4 Longobardi S, Merola B, Pivonello R, Di Rella F, Di Somma C, Colao A, Ghigo E, Camanni F \& Lombardi G. Reevaluation of growth hormone $(\mathrm{GH})$ secretion in 69 adults diagnosed as GH-deficient patients during childhood. Journal of Clinical Endocrinology and Metabolism 199681 1244-1247. (doi:10.1210/ jc.81.3.1244)

5 Bachrach LK, Hastie T, Wang MC, Narasimhan B \& Marcus R. Bone mineral acquisition in healthy Asian, Hispanic, black, and Caucasian youth: a longitudinal study. Journal of Clinical Endocrinology and Metabolism 199984 4702-4712. (doi:10.1210/ jc.84.12.4702)

6 Hutchison MR, Bassett MH \& White PC. Insulin-like growth factor-I and fibroblast growth factor, but not growth hormone, affect growth plate chondrocyte proliferation. Endocrinology 2007 148 3122-3130. (doi:10.1210/en.2006-1264)

7 Ohlsson C, Nilsson A, Isaksson OG \& Lindahl A. Effect of growth hormone and insulin-like growth factor-I on DNA synthesis and matrix production in rat epiphyseal chondrocytes in monolayer culture. Journal of Endocrinology 1992133 291-300. (doi:10.1677/joe.0.1330291)

8 Sims NA, Clement-Lacroix P, Da Ponte F, Bouali Y, Binart N, Moriggl R, Goffin V, Coschigano K, Gaillard-Kelly M, Kopchick J, Baron R \& Kelly PA. Bone homeostasis in growth hormone receptornull mice is restored by IGF-I but independent of Stat5. Journal of Clinical Investigation $2000 \mathbf{1 0 6}$ 1095-1103. (doi:10.1172/ JCI10753)
9 Lupu F, Terwilliger JD, Lee K, Segre GV \& Efstratiadis A. Roles of growth hormone and insulin-like growth factor 1 in mouse postnatal growth. Developmental Biology 2001229 141-162. (doi:10.1006/dbio.2000.9975)

10 Zhang M, Xuan S, Bouxsein ML, von Stechow D, Akeno N, Faugere MC, Malluche H, Zhao G, Rosen CJ, Efstratiadis A \& Clemens TL. Osteoblast-specific knockout of the insulin-like growth factor (IGF) receptor gene reveals an essential role of IGF signaling in bone matrix mineralization. Journal of Biological Chemistry 2002277 44005-44012. (doi:10.1074/jbc.M208 265200)

11 Drinkwater BL, Nilson K, Chesnut CH III, Bremner WJ, Shainholtz S \& Southworth MB. Bone mineral content of amenorrheic and eumenorrheic athletes. New England Journal of Medicine 1984311 277-281. (doi:10.1056/NEJM198408023 110501)

12 Greenspan SL \& Greenspan FS. The effect of thyroid hormone on skeletal integrity. Annals of Internal Medicine 1999130 750-758.

13 Tritos NA \& Biller BM. Growth hormone and bone. Current Opinion in Endocrinology, Diabetes and Obesity 200916 415-422. (doi:10.1097/MED.0b013e3283319e6d)

14 Greenspan SL, Greenspan FS, Resnick NM, Block JE, Friedlander AL \& Genant HK. Skeletal integrity in premenopausal and postmenopausal women receiving long-term L-thyroxine therapy. American Journal of Medicine 199191 5-14. (doi:10.1016/0002-9343(91)90066-7)

15 Shalet SM, Shavrikova E, Cromer M, Child CJ, Keller E, Zapletalova J, Moshang T, Blum WF, Chipman JJ, Quigley CA \& Attanasio AF. Effect of growth hormone (GH) treatment on bone in postpubertal GH-deficient patients: a 2-year randomized, controlled, dose-ranging study. Journal of Clinical Endocrinology and Metabolism 200388 4124-4129. (doi:10.1210/jc.2003030126)

16 Underwood LE, Attie KM \& Baptista J. Growth hormone (GH) dose-response in young adults with childhood-onset GH deficiency: a two-year, multicenter, multiple-dose, placebo-controlled study. Journal of Clinical Endocrinology and Metabolism $2003 \mathbf{8 8}$ 5273-5280. (doi:10.1210/jc.2003-030204)

17 Conway G, Szarras-Czapnik M, Racz K, Keller A, Chanson P, Tauber M \& Zacharin M. Treatment for 24 months with recombinant human growth hormone has a beneficial effect on bone mineral density in young adults with childhood-onset growth hormone deficiency. European Journal of Endocrinology 2009160 899-907. (doi:10.1530/EJE-08-0436)

18 Mauras N, Pescovitz OH, Allada V, Messig M, Wajnrajch MP \& Lippe B. Limited efficacy of growth hormone (GH) during transition of GH-deficient patients from adolescence to adulthood: a phase III multicenter, double-blind, randomized two-year trial. Journal of Clinical Endocrinology and Metabolism 200590 3946-3955. (doi:10.1210/jc.2005-0208)

19 Ho KK. Consensus guidelines for the diagnosis and treatment of adults with GH deficiency II: a statement of the GH Research Society in association with the European Society for Pediatric Endocrinology, Lawson Wilkins Society, European Society of Endocrinology, Japan Endocrine Society, and Endocrine Society of Australia. European Journal of Endocrinology 2007157 695-700. (doi:10.1530/EJE-07-0631)

20 Tritos NA, Greenspan SL, King D, Hamrahian A, Cook DM, Jonsson PJ, Wajnrajch MP, Koltowska-Haggstrom M \& Biller BM. Unreplaced sex steroid deficiency, corticotropin deficiency, and lower IGF-I are associated with lower bone mineral density in adults with growth hormone deficiency: a KIMS database analysis. Journal of Clinical Endocrinology and Metabolism 201196 1516-1523. (doi:10.1210/jc.2010-2662)

21 Riis P. Thirty years of bioethics: the Helsinki Declaration 1964-2003. New Review of Bioethics 20031 15-25. (doi:10. 1080/1740028032000131396)

22 Filipsson H, Monson JP, Koltowska-Haggstrom M, Mattsson A \& Johannsson G. The impact of glucocorticoid replacement regimens 
on metabolic outcome and comorbidity in hypopituitary patients. Journal of Clinical Endocrinology and Metabolism 2006913954 3961. (doi:10.1210/jc.2006-0524)

23 Brabant G, von zur Muhlen A, Wuster C, Ranke MB, Kratzsch J, Kiess W, Ketelslegers JM, Wilhelmsen L, Hulthen L, Saller B, Mattsson A, Wilde J, Schemer R \& Kann P. Serum insulin-like growth factor I reference values for an automated chemiluminescence immunoassay system: results from a multicenter study. Hormone Research 200360 53-60. (doi:10.1159/ $000071871)$

24 Genant HK, Grampp S, Gluer CC, Faulkner KG, Jergas M, Engelke K, Hagiwara S \& Van Kuijk C. Universal standardization for dual X-ray absorptiometry: patient and phantom crosscalibration results. Journal of Bone and Mineral Research 19949 1503-1514. (doi:10.1002/jbmr.5650091002)

25 Lu Y, Fuerst T, Hui S \& Genant HK. Standardization of bone mineral density at femoral neck, trochanter and Ward's triangle. Osteoporosis International $2001 \quad 12$ 438-444. (doi:10.1007/ s001980170087)

26 Prader A, Largo RH, Molinari L \& Issler C. Physical growth of Swiss children from birth to 20 years of age. First Zurich longitudinal study of growth and development. Helvetica Paediatrica Acta. Supplementum 198952 1-125.

27 Nguyen VT \& Misra M. Transitioning of children with GH deficiency to adult dosing: changes in body composition. Pituitary 200912 125-135. (doi:10.1007/s11102-008-0101-y)

28 Baroncelli GI, Bertelloni S, Sodini F \& Saggese G. Acquisition of bone mass in normal individuals and in patients with growth hormone deficiency. Journal of Pediatric Endocrinology $\mathcal{E}$ Metabolism 200316 (Suppl 2) 327-335.
29 Koltowska-Haggstrom M, Geffner ME, Jonsson P, Monson JP, Abs R, Hana V, Hoybye C \& Wollmann HA. Discontinuation of growth hormone $(\mathrm{GH})$ treatment during the transition phase is an important factor determining the phenotype of young adults with non idiopathic childhood-onset GH deficiency. Journal of Clinical Endocrinology and Metabolism $2010 \quad 95$ 2646-2654. (doi:10.1210/jc.2009-2013)

30 Jostel A, Ryder WD \& Shalet SM. The use of thyroid function tests in the diagnosis of hypopituitarism: definition and evaluation of the TSH index. Clinical Endocrinology 200971 529-534. (doi:10.1111/j.1365-2265.2009.03534.x)

31 Duncan WE, Chang A, Solomon B \& Wartofsky L. Influence of clinical characteristics and parameters associated with thyroid hormone therapy on the bone mineral density of women treated with thyroid hormone. Thyroid 1994 4 183-190. (doi:10.1089/ thy.1994.4.183)

32 Hogler W \& Shaw N. Childhood growth hormone deficiency, bone density, structures and fractures: scrutinizing the evidence. Clinical Endocrinology $2010 \mathbf{7 2}$ 281-289. (doi:10.1111/j.1365-2265. 2009.03686.x)

33 The KIMS 2004 Aetiology of growth hormone deficiency (KIMS classification list). In Growth Hormone Deficiency in Adults: 10 Years of KIMS, pp 346-348. Oxford: Oxford PharmaGenesis ${ }^{\mathrm{TM}}$ Ltd, 2004.

Received 26 January 2012

Revised version received 12 June 2012

Accepted 18 June 2012 